\title{
I.UMIBUNC
}

\section{RANCANG BANGUN DAN ANALISA ALAT PENGUPAS KOPI}

\author{
Yulia Chyntia Hariati ${ }^{1}$, Alvino Muktila Zendy ${ }^{2}$, Ahmad Husein Harahap $^{2}$, Wahyu ${ }^{2}$, Irwan A. ${ }^{2}$, \\ Jamaluddin $^{2}$, Yuni Ernita ${ }^{2}$, Sandra Melly ${ }^{2}$, Muhammad Riza Nurtam ${ }^{2}$ \\ ${ }^{1)}$ Jurusan Teknik Mesin, Fakultas Teknik, Universitas Muhammadiyah Sumatera Barat \\ ${ }^{2)}$ Program Studi Teknologi Mekanisasi Pertanian, Politeknik Pertanian Negeri Payakumbuh \\ Korespondensi: yuliachyntiahariati@gmail.com
}

\author{
Diterima : 13 Januari 2020 \\ Disetujui : 28 Februari 2020 \\ Diterbitkan : 29 Februari 2020
}

\begin{abstract}
ABSTRAK
Pengupasan kulit kopi sangat berpengaruh pada kualitas kopi yang dihasilkan. Kendala yang dihadapi dalam pengupasan kopi tradisional adalah waktu dan energi yang digunakan terlalu besar. Alat pengupas kopi berfungsi untuk mengupas atau memisahkan kulit kopi dari biji kopi dan diharapkan bisa membantu petani dalam mengupas hasil dengan maksimal dan efektif. Alat pengupas kopi berkapasitas $200 \mathrm{~kg} / \mathrm{jam}$. Hasil analisa ekonomi teknik alat pengupas kopi didapat biaya tetap Rp. 1.179.630/tahun, biaya tidak tetap Rp. 16.069/jam, biaya pokok Rp. 82/kg dan Break Event Point (BEP) $1.567 \mathrm{~kg} / \mathrm{tahun}$.
\end{abstract}

\section{Keywords: kopi, pengupas}

\begin{abstract}
Stripping coffee skin is very influential on the quality of coffee produced. Constraints faced in stripping traditional coffee is the time and energy used is too large. The coffee peeler has the function of peeling or separating the skin of the coffee from the coffee beans and is expected to help farmers to peel results maximally and effectively. Coffee peeler with a capacity of 200 $\mathrm{kg} / \mathrm{hour}$. The results of an economic analysis of the coffee peeling technique are fixed costs Rp. 1,179,630 / year, variable costs Rp. 16,069/ hour, basic cost of Rp. $82 / \mathrm{kg}$ and break event point (BEP) 1,567 kg / year.
\end{abstract}

Keywords: coffee, peeler

\section{PENDAHULUAN}

Indonesia merupakan salah satu negara penghasil kopi di dunia. Jenis kopi yang dihasilkan adalah jenis Robusta dengan karakteristik biji kopi berbentuk bulat. Jumlah biji perkilogram adalah 2300-4000, tumbuh di ketinggian 400-700 m dari permukaan laut dengan suhu 25-300 C. Biji kopi muda memiliki warna hijau dan pada saat matang akan berubah menjadi merah. Periode kematangan buah yaitu 9-10 bulan. (Riza, 2014) 


\section{I.UMIBUNG}

Kabupaten Limapuluh Kota merupakan salah satu penghasil kopi terbesar di Sumatera Barat. Berdasarkan data BPS Sumatera Barat tercatat di Kabupaten Limapuluh Kota menghasilkan kopi sebanyak 2.623 ton dengan luas lahan 2.777 hektar pada tahun 2015 . Sumatera Barat menghasilkan 33.579 Ton kopi dengan luas lahan 42.023 hektar pada tahun 2015 (BPS,2016; BPS, 2019).

Tujuan pengupasan kulit buah adalah untuk memisahkan biji kopi dengan kulit tanduk (Asni \& Meilin, 2015). Pengupasan kulit kopi sangat berpengaruh pada kualitas kopi yang dihasilkan. Umumnya pada perkebunan rakyat, pengupasan kulit kopi masih menggunakan alat pengupas kulit kopi manual dan semi mekanis. Pengupasan kulit kopi secara tradisional tersebut membutuhkan waktu yang lama dan energi yang besar. Alat ini digerakkan oleh tenaga manusia untuk memisahkan antara kulit kopi dengan biji kopi sehingga memiliki keterbatasan dalam kapasitas hasilnya. Alat pengupas kopi yang dibuat pada penelitian ini berfungsi untuk mengupas atau memisahkan kulit kopi dari biji kopi yang bisa membantu petani dalam mengupas kopi dengan hasil maksimal dan efektif dalam pengunaannya.

\section{METODE PENELITIAN}

\section{Tempat dan Waktu Penelitian}

Pembuatan alat pengupas kopi ini dilakukan di bengkel Politeknik Pertanian Negeri Payakumbuh dimulai pada September sampai dengan Desember 2018.

\section{Alat dan Bahan}

Alat yang dibutuhkan untuk pembuatan alat pengupas kopi dapat dilihat pada Tabel 1.

Table 1. Alat-alat yang dibutuhkan

\begin{tabular}{lll}
\hline No & \multicolumn{1}{c}{ Jenis Alat } & Jumlah \\
\hline 1 & Msin las listrik & 2 unit \\
2 & Mesin bubut & 1 unit \\
3 & Mesin frais & 1 unit \\
4 & Mesin gerinda tangan & 2 unit \\
5 & Mesin gerinda potong & 1 unit \\
6 & Las asetilen & 1 unit \\
7 & Mesin bor & 1 unit \\
8 & Rol siku & 2 buah \\
9 & Palu & 2 buah \\
10 & Meteran & 1 buah \\
11 & Mesin gergaji besi & 1 buah \\
12 & Mesin pemotong plat & 1 unit \\
13 & Mesin penggulung plat & 1 unit \\
14 & Gerinda statis & 1 unit \\
15 & Jangka sorong & 1 buah \\
\hline
\end{tabular}




\section{I.UMIAUNG}

Bahan yang dibutuhkan dalam menunjang pembutan alat pengupas kopi dapat dilihat pada Tabel 2.

Tabel 2. Bahan-bahan yang digunakan

\begin{tabular}{llll}
\hline No & \multicolumn{1}{c}{ Nama Alat } & Satuan & Kuantitas \\
\hline 1 & Besi strip 20 mm x 2 mm x 40 mm & Batang & $11 / 2$ Batang \\
2 & Besi siku 40 mm x 3 mm x 600 mm & Batang & $11 / 2$ Batang \\
3 & Besi plat 1,5mm & Lembar & $1 / 2$ Lembar \\
4 & Kawat & Meter & $10 \mathrm{~m}$ \\
5 & Elektroda 2,6 & Kotak & 1 Kotak \\
6 & Besi poros 1 inchi & Meter & $1 \mathrm{~m}$ \\
7 & Bantalan UCP 205 & Buah & 4 Buah \\
8 & Sabuk V & Buah & 1 Buah \\
9 & Puli16 inci & Buah & 1 Buah \\
10 & Puli 2,4 inci & Buah & 1 Buah \\
11 & Gigi Tarik & Buah & 2 Buah \\
12 & Rantai & Cm & $30 \mathrm{~cm}$ \\
13 & Baut 10 mm & Buah & 25 Buah \\
14 & Baut 12 mm & Buah & 12 Buah \\
15 & Baut 14 mm & Buah & 4 Buah \\
16 & Motor listrik 1 hp & Buah & 1 Buah \\
17 & Cat $(500 \mathrm{~mm} \mathrm{)}$ & Kaleng & 1 Kaleng \\
18 & Kuas & Buah & 1 Buah \\
\hline
\end{tabular}

\section{Tahap Pembuatan Alat Pengupas Kopi}

Proses pembuatan alat pengupas kopi ini dapat dilihat pada Gambar 1.

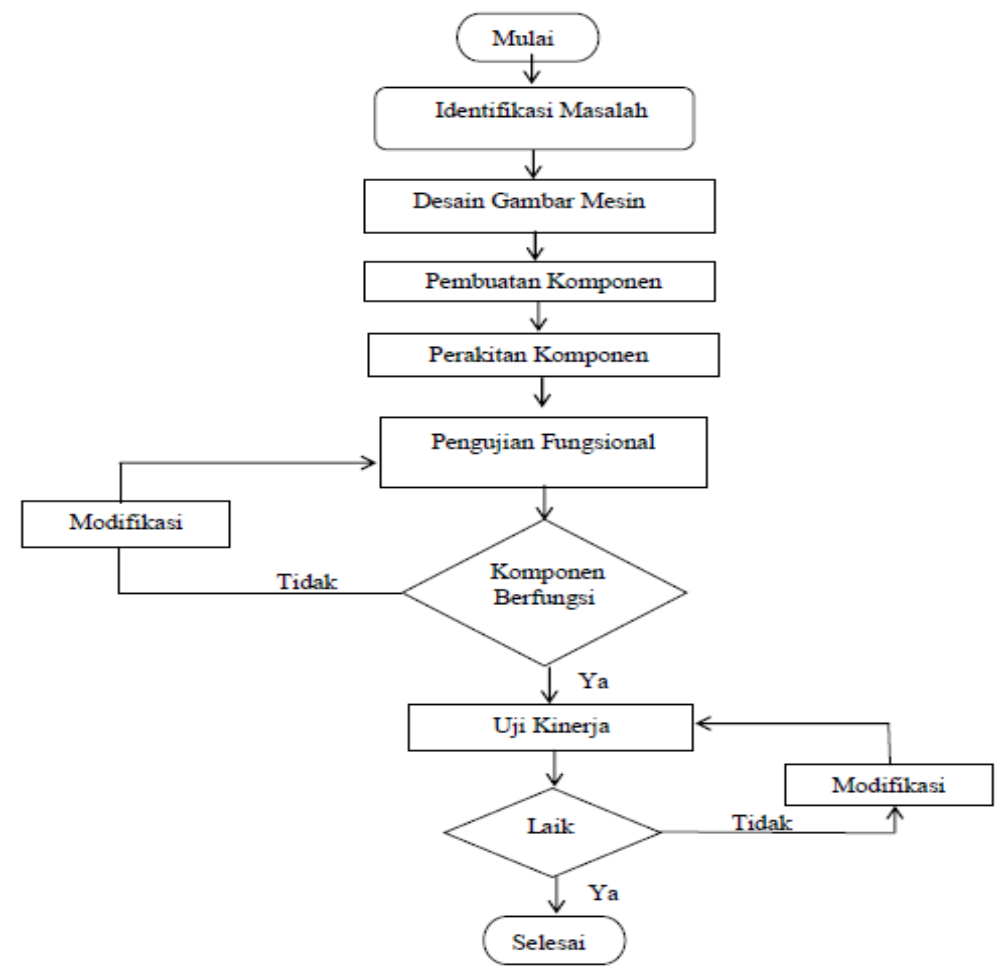

Gambar 1 Diagram alir tahap pembuatan alat pengupas kopi 


\section{I.UMIBUNG}

\section{Rancangan Alat}

Rancangan struktural menjelaskan tentang dimensi atau ukuran setiap komponen alat pengupas kopi. Rancangan fungsional menjelaskan tentang fungsi dari setiap komponen pembuatan alat pengupas kopi. Rancangan fungsional dan struktural alat pengupas kopi adalah:

\section{Rangka}

Rangka adalah tempat kedudukan komponen alat pengupas kopi. Rangka terbuat dari besi siku ukuran $30 \mathrm{~mm}$ x $30 \mathrm{~mm}$ x $3 \mathrm{~mm}$ dengan panjang $80 \mathrm{~cm}$, lebar $36,5 \mathrm{~cm}$, dan tinggi $45 \mathrm{~cm}$. Rangka dapat dilihat pada Gambar 2.

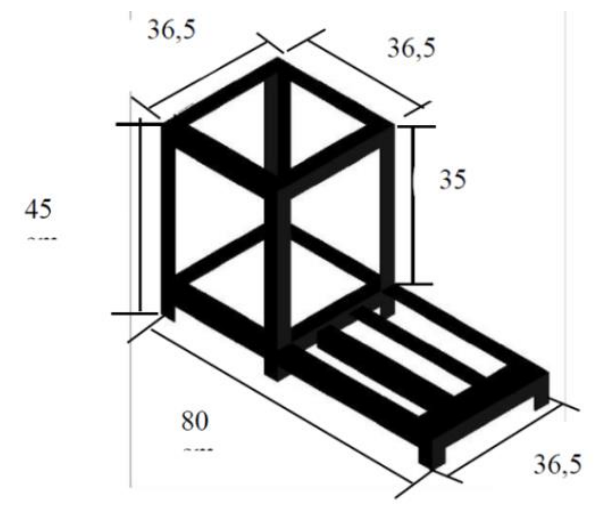

Gambar 2. Rangka

\section{Hopper}

Hopper berfungsi sebagai tempat memasukkan kopi yang akan dikupas. Hopper terbuat dari besi plat dengan ketebalan 1,5 mm dengan tinggi $23 \mathrm{~cm}$. Hopper dapat dilihat pada Gambar 3.

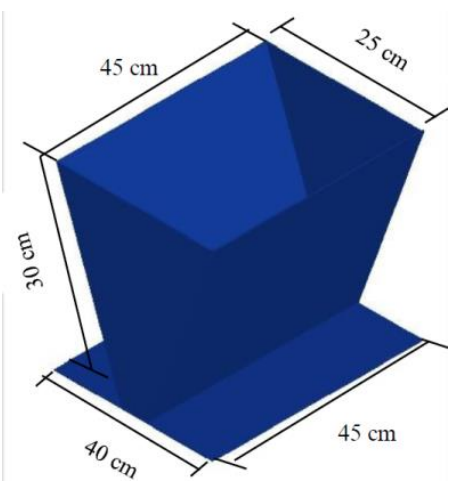

Gambar 3. Hopper

Outlet

Outlet berfungsi tempat keluar kopi hasil pengupasan. Outlet terbuat dari besi plat dengan ketebalan 1,5 mm dengan lebar $30 \mathrm{~cm}$, panjang $45 \mathrm{~cm}$, dan tinggi $5 \mathrm{~cm}$. Outlet dapat dilihat pada Gambar 4. 


\section{I.UMIBUNG}

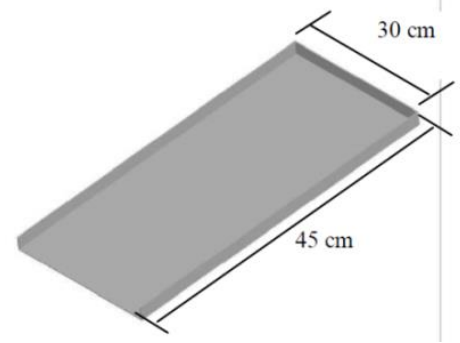

Gambar 4. Outlet

Unit pengupas

Unit pengupas berfungsi sebagai pengupas biji kopi dari kulitnya. Unit pengupas terbuat dari kayu berdiameter $18 \mathrm{~cm}$ dan kawat stainles. Unit pengupasan dapat dilihat pada Gambar 5.

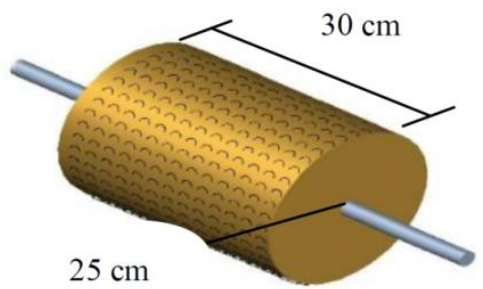

Gambar 5. Unit pengupas

Penggilas

Penggilas berfungsi sebagai penekan kopi dengan gigi pengupas, terbuat dari kayu yang dilapisi besi plat supaya kuat dalam menahan kopi. Penggilas memiliki panjang $30 \mathrm{~cm}$, lebar 10 $\mathrm{cm}$ dan tebal $15 \mathrm{~cm}$. Penggilas bisa dilihat pada Gambar 6 .

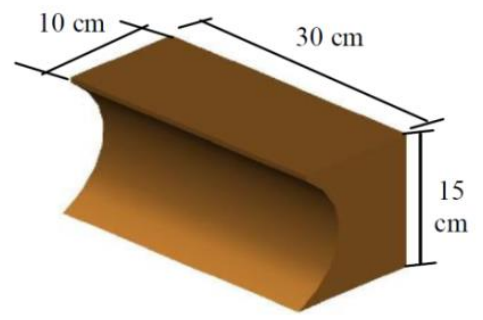

Gambar 6. Penggilas

Rol pemasukan

Rol pemasukan berfungsi sebagai pengantar kopi masuk ke gigi pengupas. Rol pemasukan memiliki panjang $30 \mathrm{~cm}$. Rol pemasukkan bisa dilihat pada Gambar 7.

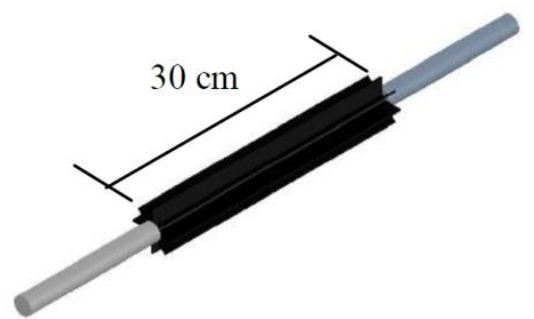

Gambar 7. Rol pemasukan 


\section{I.UMIBUNG}

Dinding pengupas

Dinding pengupas berperan sebagai penopang komponen pengupas yang terbuat dari plat tebal $2 \mathrm{~mm}$ dengan panjang $36.5 \mathrm{~cm}$, lebar bagian bawah $24 \mathrm{~cm}$ dan lebar bagian atas $17 \mathrm{~cm}$. Dinding pengupas dapat dilihat pada Gambar 8.

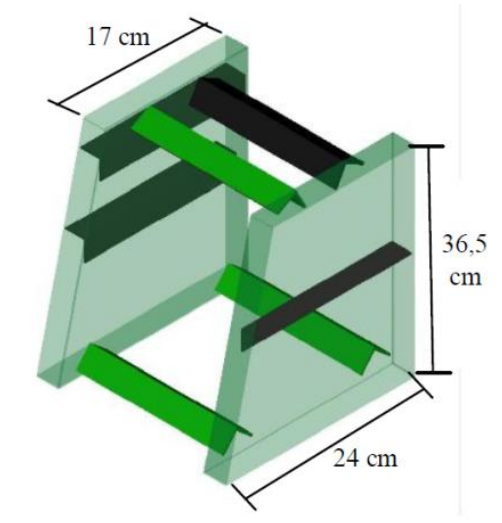

Gambar 8. Dinding pengupas

Unit tranmisi

Unit tranmisi digunakan untuk menyalurkan tenaga ke unit pengupas. Puli motor berperan sebagai penghubung tranmisi pada motor. Puli berdiameter 2 inci yang dipasang di motor listrik 1 HP. Sabuk V berfungsi sebagai penghubung puli motor dengan puli pengupas, karena dengan menggunakan sabuk V lebih hemat biaya dan memungkinkan jarak yang panjang. Unit transmisi dapat dilihat pada Gambar 9.

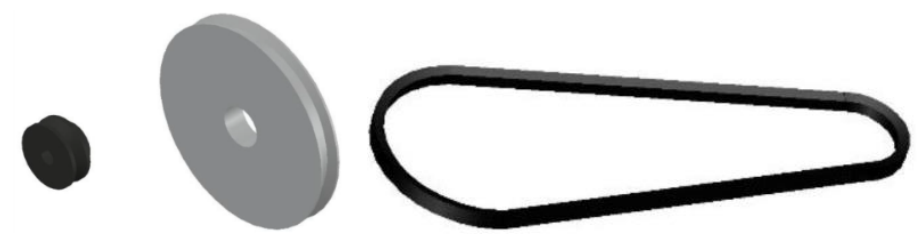

Gambar 9. Unit transmisi

Motor listrik

Motor listrik berfungsi sebagai penggerak utama mesin pengupas kopi, yang merupakan motor listrik 3 fasa. Motor listrik memiliki daya 1 HP dengan 1400 RPM. Motor listrik dapat dilihat pada Gambar 10.

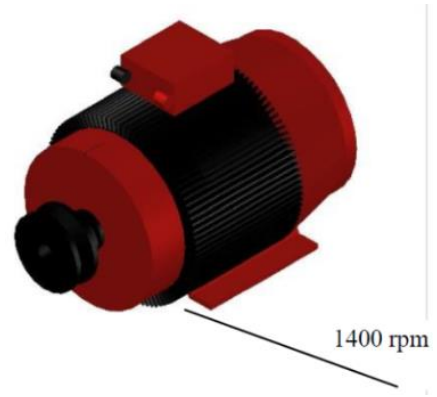

Gambar 10. Motor listrik 


\section{I.UMIBUNG}

\section{HASIL DAN PEMBAHASAN}

\section{Pengambilan Data Lapangan}

Hasil pengambilan data lapangan berupa data titik koordinat dilakukan setelah pembukaan jalan rintisan. Pengambilan titik koordinat dilapangan dilakukan sebanyak +145 titik. Data titik koordinat yang diambil adalah dalam format data geografis. Data diolah supaya dapat menggambarkan kondisi lapangan. Data titik yang didapat dihubungkan untuk membuat batasan lahan dan data ketinggian tempat (elevasi) diolah untuk menggambarkan garis kontur dari lahan.

Alat pengupas kopi memiliki panjang $80 \mathrm{~cm}$, lebar $34,5 \mathrm{~cm}$, dan tinggi $100 \mathrm{~cm}$. Alat pengupas kopi digerakkan oleh motor listrik yang memutar puli dan diteruskan oleh sabuk V untuk memutar puli yang terpasang di poros gigi pengupas. Gigi pengupas berputar dan poros akan memutar roda gigi untuk menggerakan rol pemasuk kopi. Kopi dimasukkan ke dalam hopper dan akan menuju ke rol masuk dan menuju silinder pengupas. Pada silinder pengupas, kopi ditekan oleh gigi pengupas ke dinding pengupas sehingga kulit kopi pecah. Biji kopi yg pecah keluar melalui outlet. Alat pengupas kopi dapat dilihat ada Gambar 11.

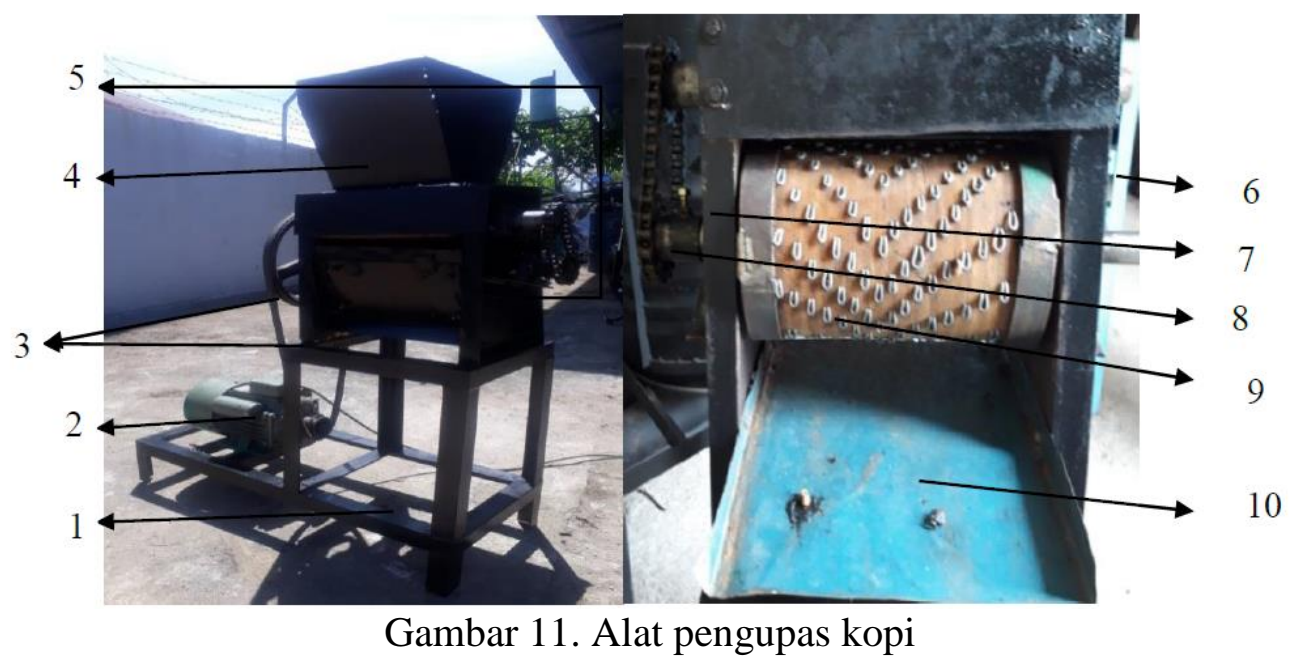

Keterangan gambar:

Gambar 11. Alat pengupas kopi

1. Kerangka utama

2. Motor listrik

3. Pulley dan V-belt

4. Hopper

5. Dinding pengupas

6. Kerangka pengupas

7. Roda gigi

8. Rantai

9. Gigi pengupas

10. Outlet 


\section{I.UMIRUNC \\ 1.}

\section{Uji Kinerja}

\section{Pengujian manual}

Dari hasil pengujian yang dilakukan dengan cara manual mengunakan lesung didapat hasil seperti Tabel 3.

Tabel 3. Hasil pengujian kapasitas pengujian manual

\begin{tabular}{llllll}
\hline \multirow{2}{*}{ Pengujian } & \multirow{2}{*}{$\begin{array}{c}\text { Berat } \\
\text { Kopi }\end{array}$} & \multirow{2}{*}{$\begin{array}{c}\text { Banyak } \\
\text { Air (Liter) }\end{array}$} & $\begin{array}{c}\text { Pengupasan } \\
(\mathrm{Kam})\end{array}$ & $\begin{array}{c}\text { Buah Utuh } \\
(\mathrm{Kg})\end{array}$ & $\begin{array}{c}\text { Buah Terkelupas } \\
(\mathrm{Kg})\end{array}$ \\
\hline 1 & 1 & 0.5 & 0.083 & 0.1 & 0.9 \\
2 & 1 & 0.5 & 0.083 & 0.15 & 0.85 \\
Jumlah & 2 & 1 & 0.166 & 0.25 & 1.75 \\
Rata-rata & 1 & 0.5 & 0.083 & 0.125 & 0.875 \\
\hline
\end{tabular}

Dari pengujian diatas dapat disimpulkan bahwa rata-rata untuk berat bahan $1 \mathrm{~kg}$ kopi, waktu yang dibutuhkan 4,98 menit atau 0,083 jam dan kapasitas 12,05 kg/jam.

Kapasitas alat $=\frac{\text { Berat bahan yang dikupas }(\mathrm{kg})}{\text { Waktu yang digunakan }(\mathrm{jam})}=\frac{0,875 \mathrm{~kg}}{0.083 \mathrm{jam}}=10.05 \mathrm{~kg} / \mathrm{jam}$

\section{Pengujian Alat pengupas kopi}

Hasil pengujian pada alat pengupas kopi dengan 204,97 RPM dapat dilihat pada Tabel 4.

Tabel 4. Kapasitas alat pengupas kopi

\begin{tabular}{|c|c|c|c|c|c|}
\hline \multirow[b]{2}{*}{ Pengujian } & \multirow{2}{*}{$\begin{array}{c}\text { Berat } \\
\text { Kopi }(\mathrm{Kg})\end{array}$} & \multirow{2}{*}{$\begin{array}{c}\text { Banyak } \\
\text { Air (Liter) }\end{array}$} & \multirow{2}{*}{$\begin{array}{c}\text { Waktu } \\
\text { Pengupasan } \\
\text { (Jam) }\end{array}$} & \multicolumn{2}{|c|}{ Hasil Pengupasan } \\
\hline & & & & $\begin{array}{l}\text { Buah Utuh } \\
\text { (Kg) }\end{array}$ & $\begin{array}{c}\text { Buah Terkelupas } \\
(\mathrm{Kg})\end{array}$ \\
\hline 1 & 5 & 3 & 0.025 & 0.7 & 4.3 \\
\hline 2 & 4 & 3 & 0.020 & 0.8 & 3.2 \\
\hline Jumlah & 9 & 6 & 0.045 & 0.15 & 7.7 \\
\hline Rata-rata & 4,5 & 3 & 0.0225 & 0.075 & 3.85 \\
\hline
\end{tabular}

Dari pengujian diatas dapat disimpulkan bahwa hasil rata-rata untuk berat bahan 4,5 kg kopi, waktu yang dibutuhkan 1,35 menit atau 0,0225 jam dan kapasitas 200 $\mathrm{kg} / \mathrm{jam}$.

Kapasitas alat $=\frac{\text { Berat bahan yang dikupas }(\mathrm{kg})}{\text { Waktu yang digunakan }(\mathrm{jam})}=\frac{3,85 \mathrm{~kg}}{0.0225 \mathrm{jam}}=171 \mathrm{~kg} / \mathrm{jam}$

Dari hasil pengujian yang dilakukan didapatkan kapasitas alat pengupas kopi 171 $\mathrm{kg} / \mathrm{jam}$, sedangkan mengupas kopi dengan menggunakan lesung didapat 10,05 kg/ jam. Jadi dapat disimpulkan bahwa dengan menggunakan alat pengupas kopi, pengupasan kopi dapat lebih cepat daripada dengan cara tradisional/manual. 


\section{I.UMIRUNC}

\section{Rendemen alat pengupas kopi}

Setelah dilakukan pengujian terhadap alat pengupas kopi maka didapat rendemen hasil sebagai berikut:

$\mathrm{sr}=\frac{\text { Berat bahan yang telah dikupas }}{\text { Jumlah bahan yang dimasukkan }}=\frac{3,85 \mathrm{~kg}}{4,5 \mathrm{~kg}} \times 100 \%=85,5 \%$

\section{Persentase biji tidak terkupas}

Biji tidak terkupas yaitu buah kopi yang tidak pecah atau masih utuh yang didapatkan dari uji kinerja yang dilakukan. Persentase biji tidak terkupas adalah:

Persentase biji tidak terkupas $=\frac{\text { Berat kopi yang tidak terkupas }}{\text { Berat buah kopi awal }}=\frac{3,85 \mathrm{~kg}}{4,5 \mathrm{~kg}} \times 100 \%=85,5 \%$

\section{Analisis Ekonomi}

Analisa ekonomi serupa pada penelitian ini telah dilakukan oleh Prayogi et al.(2018); Azima et al. (2018); Novita et al, (2019). Analisis yang digunakan pada biaya operasional alat pengupas kopi sebagai berikut:

Harga jual alat $(\mathrm{P})=\mathrm{Rp} .4 .681 .075$

Umur ekonomis $(\mathrm{N})=5$ tahun

Harga akhir $(\mathrm{S}) \quad=10 \% \times \mathrm{P}$

Bunga modal $(\mathrm{i}) \quad=12 \% /$ tahun

Jam kerja/tahun $(X)=2.400$ jam/tahun

Jam kerja/hari $\quad=8 \mathrm{jam}$

Upah operator = Rp. $80.000 /$ hari

Jumlah operator $\quad=1$ orang

Upah sewa alat(R) = Rp. $250 / \mathrm{kg}$

Kapasitas alat $\quad=833 \mathrm{~kg} / \mathrm{jam}$

\section{Biaya tetap (Fixed cost)}

Biaya tetap merupakan biaya yang dikeluarkan meskipun alat tersebut tidak di operasikan. Biaya tetap dapat dihitung sebagai berikut:

Biaya penyusutan

$\mathrm{D}=\frac{\mathrm{P}-\mathrm{S}}{\mathrm{N}}=\frac{\mathrm{Rp} \cdot 4 \cdot 681.075-\mathrm{Rp} .468 .107}{5 \text { tahun }}=\mathrm{Rp} .842 .594 /$ tahun

Keterangan:

$\mathrm{D}=$ Biaya penyusutan (Rp/tahun)

$\mathrm{P}=$ Harga jual $(\mathrm{Rp})$

$\mathrm{S}=$ Harga akhir $(\mathrm{Rp}) / 10 \% \mathrm{xp}$ 


\section{I.UMIRUNC}

$\mathrm{N}=$ Perkiraan umur ekonomis (tahun)

Bunga modal

$I=\frac{i(P)(N+1)}{2 N}=\frac{12 \%(R p .4 .681 .075)+(5+1)}{2 \times 5 \text { tahun }}=$ Rp. 337.037/tahun

Keterangan:

$\mathrm{I}=$ Bunga modal (Rp/tahun)

Biaya tetap $=$ Biaya penyusutan + Bunga modal $=$ Rp. 842.594/tahun + Rp. 337.037/tahun = Rp. 1.179.631/tahun

\section{Biaya tidak tetap (Variable cost)}

Biaya tidak tetap merupakan biaya yang dikeluarkan tergantung sedikit atau banyaknya alat dan mesin yang akan dioperasikan dan biaya ini sangat dipengaruhi oleh jam kerja pemakaian alat, (Irwan \& Novita, 2016). Biaya tidak tetap untuk alat pengupas kopi adalah:

Upah operator

Upah operator $=\frac{\text { Upah }\left({ }^{R p} / \text { Hari }\right) x \text { Jumlah operator }}{\text { Jam } \text { kerja } / \text { hari }}=\frac{\text { Rp.80.000/hari } x 1}{8 \mathrm{Jam} / \text { hari }}=\mathrm{Rp} .10 .000 / \mathrm{jam}$

Biaya perawatan

Biaya perawatan $=\frac{1.2 \% x(P-S)}{100 \mathrm{jam}}=\frac{1.2 \% x(R p .4 .681 .075-R p .468 .107)}{100 \mathrm{jam}}=\mathrm{Rp} .505 / \mathrm{jam}$

Biaya listrik

Biaya listrik $=\mathrm{kW} * \mathrm{Rp} / \mathrm{kWh}=0.75 \mathrm{~kW} * \mathrm{Rp} .1 .352 / \mathrm{kW}$ jam $=\mathrm{Rp} .1 .014 / \mathrm{jam}$

Biaya tidak tetap $=$ Upah operator + Biaya perawatan + Biaya listrik

$$
=\text { Rp. 10.000/jam }+ \text { Rp. 505/jam }+ \text { Rp. 1.014/jam = Rp. 11.519/Jam }
$$

\section{Biaya pokok}

Biaya pokok merupakan biaya yang diperlukan alat untuk setiap produksi. Biaya pokok dapat dihitung sebagai berikut:

$B P=\frac{\frac{B T}{X}+B T T}{C}=\frac{\frac{R p \cdot 1.179 .630 / \text { tahun }}{2400 \mathrm{jam} / \mathrm{tahun}}+R p \cdot 11.519 / \mathrm{jam}}{200 \mathrm{~kg} / \mathrm{jam}}=\mathrm{Rp} .60 / \mathrm{kg}$

Dimana:

$\mathrm{BP}=$ Biaya pokok $(\mathrm{Rp} / \mathrm{jam})$

$\mathrm{X}=$ Jumlah jam kerja (jam/tahun)

$\mathrm{C}=$ Kapasitas alat $(\mathrm{kg} / \mathrm{jam})$ 


\section{I.UMIRUNC}

\section{Break event point (BEP)}

Break event point (BEP) yaitu suatu titik dimana biaya atau pengeluaran dan pendapatan seimbang sehingga tidak terdapat keuntungan ataupun kerugian. Break event point dapat dihitung sebagai berikut:

$\mathrm{BEP}=\frac{\mathrm{BT}}{\mathrm{R}-\left(\frac{\mathrm{BTT}}{\mathrm{C}}\right)}=\frac{\mathrm{Rp} \cdot 1 \cdot 179.630 / \mathrm{tahun}}{\mathrm{Rp} \cdot 833 / \mathrm{kg}-\left(\frac{\mathrm{Rp} \cdot 11.519 / \mathrm{jam}}{200 \mathrm{~kg} / \mathrm{jam}}\right)}=1.521 \mathrm{~kg} / \mathrm{tahun}$

Keterangan:

$\mathrm{BEP}=$ Break event point ( $\mathrm{kg} / \mathrm{tahun})$

$\mathrm{R}=$ Upah sewa alat $(\mathrm{Rp} / \mathrm{kg})$

\section{KESIMPULAN DAN SARAN}

Alat pengupas kopi ini memiliki panjang $80 \mathrm{~cm}$, lebar $34,5 \mathrm{~cm}$, dan tinggi 100 $\mathrm{cm}$. Alat pengupas kopi ini menggunakan dua buah poros yang digerakkan oleh motor listrik 1hp dengan 1400 RPM. Alat pengupas kopi ini memiliki kapasitas 200 kg/jam. Untuk hasil perhitungan yang dilakukan dengan menggunakan rumus analisa ekonomi teknik didapat biaya pokok Rp. 60/kg dan Break Event Point (BEP) 1.521 kg/tahun. Untuk dinding pengupas dan poros pengupas diberi penyetelan kerapatan agar hasil dari pengupasan kopi dapat di maksimalkan lagi. Pada saat proses pengupasan kulit kopi sebaiknya sesekali air dimasukan agar buah kopi tidak tersangkut di antara dinding pengupas dan poros pengupas.

\section{REFERENSI}

Asni, N. \& Meilin, A. 2015. Teknologi Penanganan Pascapanen dan Pengolahan Hasil Kopi Liberika Tungkal Komposit (LIBTUKOM). Jambi : Badan pengkajian Teknologi Petanian Jambi.

Azima, F., Putera, P., Oktaviyani, Zulfani, R., \& Hernando, R. 2018. Rancang Bangun Mesin Pengiris Buah Pinang Muda Tipe Horizontal. Agroteknika, 1(2), 63-76. https://doi.org/10.32530/agtk.v1i2.23

Badan Pusat Statistik (BPS). 2016. Luas Tanaman Perkebunan Kopi Arabika dan Kopi Robusta (hektar), 2001-2015. Diperoleh dari: https://sumbar.bps.go.id/statictable/2016/11/03/404/luas-tanaman-perkebunankopi-arabika-dan-kopi-ro(busca-hektar-2001-2015.html diakses pada 8 Januari 2019. 


\section{I.UMIBUNG}

Badan Pusat Statistik (BPS). 2019. Produksi Kopi Perkebunan Rakyat, 2007-2017. Diperoleh dari: https://sumbar.bps.go.id/dynamictable/2016/11/17/40/produksikopi-perkebunan-rakyat-2007-2015.html diakses pada 8 Januari 2019.

Irwan \& Novita, S. A. 2016. Buku Kerja Praktek Mahasiswa (BKPM). Ekonomi Teknik. Payakumbuh: Politeknik Pertanian Negeri Payakumbuh.

Novita, S., Hendra, H., Jamaluddin, J., Makky, M., \& Fahmi, K. 2019. Design and Performance Test of Rubber Grinding Machine. Journal of Applied Agricultural Science and Technology, 3(2), 299-308. https://doi.org/10.32530/jaast.v3i2.112

Prayogi, G., Wahyudy, R., Yogaswara, S., \& Primayuldi, T. 2018. Rancang Bangun Mesin Pengupas Tempurung Kelapa. Agroteknika, 1(2), 7788.https://doi.org/10.32530/agtk.v1i2.24

Riza, M. M.. 2014. Rancang Bangun Mesin Pengupas Kopi Dengan Kapasitas 10 kg. (Skripsi). Banjarmasin : Politeknik Negeri Banjarmasin. 